\title{
Comparison of the fine-scale genetic structure of three dipterocarp species
}

\author{
Y Takeuchi ${ }^{1,6}$, S Ichikawa ${ }^{2}$, A Konuma ${ }^{3,7}$, N Tomaru ${ }^{1}$, K Niiyama ${ }^{5}$, SL Lee ${ }^{4}$, N Muhammad ${ }^{4}$ and \\ Y Tsumura ${ }^{3}$ \\ ${ }^{1}$ School of Agricultural Science, Nagoya University, Nagoya 464-8601, Japan; ${ }^{2}$ Japan Wildlife Research Center, Shitaya, Taitou-ku, Tokyo \\ 110-8676, Japan; ${ }^{3}$ Department of Forest Genetics, Forestry and Forest Products Research Institute, Tsukuba, Ibaraki 305-8687, Japan; \\ ${ }^{4}$ Forest Research Institute Malaysia, Kepong 52109, Kuala Lumpur, Malaysia; ${ }^{5}$ Department of Forest vegetation, Forestry and Forest \\ Products Research Institute, Tsukuba, Ibaraki 305-8687, Japan
}

\begin{abstract}
We investigated the fine-scale genetic structure of three tropical-rainforest trees, Hopea dryobalanoides, Shorea parvifolia and S. acuminata (Dipterocarpaceae), in Peninsular Malaysia, all of which cooccurred within a 6-ha plot in Pasoh Forest Reserve. A significant genetic structure was found in $H$. dryobalanoides, weaker (but still significant) genetic structure in $S$. parvifolia and nonsignificant structure in $S$. acuminata. Seeds of all three species are wind dispersed, and their flowers are thought to be insect pollinated. The most obvious difference among these species is their height: $S$. parvifolia and $S$. acuminata are
\end{abstract}

canopy species, whereas $H$. dryobalanoides is a subcanopy species. Clear differences were also found among these species in their range of seed dispersal, which depends on the height of the release point; so taller trees disperse their seed more extensively. The estimates of seed dispersal area were consistent with the degree of genetic structure found in the three species. Therefore, tree height probably had a strong influence on the fine-scale genetic structure of the three species.

Heredity (2004) 92, 323-328, advance online publication, 21 January 2004; doi:10.1038/sj.hdy.6800411

Keywords: Hopea dryobalanoides; microsatellite; relatedness; Shorea parvifolia; Shorea acuminata; SSR

\section{Introduction}

Ecological geneticists have intensively discussed the establishment of the spatial genetic structure in plant populations and the hypothesis that limited gene dispersal should lead to genetic differentiation within a continuous population (Nason et al, 1997). In such cases, mating does not occur randomly at the whole-population scale, but is affected by the distance between individuals, according to the isolation-by-distance model (Wright, 1943). Limited gene dispersal can produce the fine-scale genetic structure even within a random mating population. The studies on the spatial genetic structure in temperate and tropical trees have detected a positive relationship between genetic relatedness and spatial distance, which could be explained by limited gene dispersal or the involvement, to some degree, of vegetative reproduction (Berg and Hamrick, 1995; Boshier et al, 1995; Alvarez-Buylla et al, 1996; Ueno et al, 2000). On the other hand, some studies have reported that several species have weak spatial genetic structure, due to extensive seed or pollen dispersal (Hamrick et al, 1993; Geburek and Trippknoeles, 1994; Doligez and Joly,

Correspondence: Y Tsumura. Current address: Department of Forest Genetics, Forestry and Forest Products Research Institute, Tsukuba, Ibaraki 305-8687, Japan. E-mail: ytsumu@ffpri.affrc.go.jp

${ }^{6}$ Current address: Center for Ecological Research, Kyoto University, 509-3 Ohtsuka, Kamitanakami Hirano-cho, Ohtsu, Shiga 520-2113, Japan.

${ }^{7}$ Current address: Graduate School of Science and Technology, Niigata University, Niigata 950-2101, Japan.

Received 27 June 2002; revised 13 July 2003; accepted 18 September 2003
1997). The genetic structure is also influenced by gene dispersal mechanisms; the genetic structure of winddispersed species tends to be greater than that of animaldispersed species (Hamrick et al, 1993, Loiselle et al, 1995, Hamrick and Nason, 1996). Thus, knowledge of the extent of gene dispersal is crucial to understanding genetic structure within plant populations.

Hopea dryobalanoides Miq. (Dipterocarpaceae) is a subcanopy tree widely distributed in Malaya, Sumatra and Borneo (Ashton, 1982). It has hermaphrodite flowers and is probably fly pollinated (Appanah, 1987). Shorea parvifolia Dyer and S. acuminata Dyer are canopy or emergent trees found in Malaya, Sumatra and Borneo (Ashton, 1982). Both S. parvifolia and S. acuminata have hermaphrodite flowers, and the main flower visitors are thrips and/or small beetles (Appanah, 1981). Seeds of all three species are dispersed by wind or gravity. These three species occur in sympatry in lowland dipterocarp forests and there is little difference in their density. The major difference among these three species is their height. The main objectives of this study were to compare the spatial genetic structure of the three dipterocarp species, and to evaluate the effect of seed dispersal distance on their genetic structure.

\section{Materials and methods}

Study site and sample collection

This study was conducted in Pasoh Forest Reserve in Peninsular Malaysia $\left(2^{\circ} 58^{\prime} \mathrm{N}, 102^{\circ} 18^{\prime} \mathrm{E}, 75-150 \mathrm{~m}\right.$ above sea level). The reserve is a lowland dipterocarp forest, characterized by high proportions of Dipterocarpaceae 
(Manokaran et al, 1992). A permanent 6-ha ecological research plot (200-300 m) was established in 1994, where the location and species of all individual trees, with a diameter at breast height $(\mathrm{dbh})$ greater than $5 \mathrm{~cm}$, have been recorded at least three times every 2 years to monitor growth, mortality and recruitment for population dynamic study.

In this study, leaves or inner bark samples were collected from all mapped individuals of $H$. dryobalanoides (64 trees), S. parvifolia (50 trees) and S. acuminata (46 trees) in the plot (Figure 1).

DNA extraction and microsatellite analysis

Total DNA was extracted from leaves or inner bark samples of each individual using a modified CTAB method (Tsumura et al, 1996). Following crude DNA extraction, these DNA samples were purified with a FastDNA Kit (Bio 101, Inc.)

Nine primer pairs developed in S. curtisii (Ujino et al, 1998) and six developed in Neobalanocarpus heimii (Iwata et al, 2000) were tested, and suitable primer pairs were selected. Five primer pairs (Shc02, Shc09, Nhe004, Nhe005 and Nhe018) were used in H. dryobalanoides, four (Shc02, Shc03, Shc04 and Nhe05) in S. parvifolia and four (Shc03, Shc04, Shc09 and Nhe005) in S. acuminata. PCR reaction mixtures $(10 \mu \mathrm{l})$ contained $1 \times$ PCR Buffer (Gibco BRL Co Ltd), $1.5 \mathrm{mM} \mathrm{MgCl}, 0.2 \mathrm{mM}$ of each dNTP, $200 \mathrm{nM}$ of each primer (one of each pair was fluorescently labeled), $1 \mathrm{ng}$ of template DNA and $0.25-0.5 \mathrm{U}$ of Taq polymerase (Gibco BRL Co Ltd). PCR amplification was carried out for $3 \mathrm{~min}$ at $94^{\circ} \mathrm{C}$, followed by 30 cycles of $30 \mathrm{~s}$ at $94^{\circ} \mathrm{C}$,

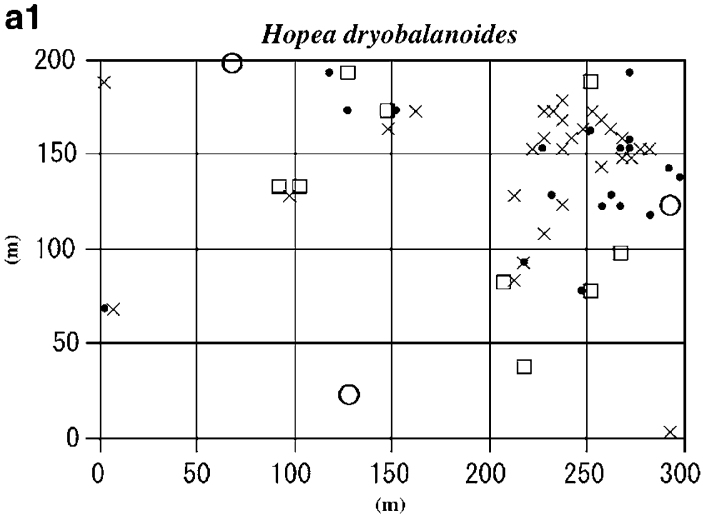

b1

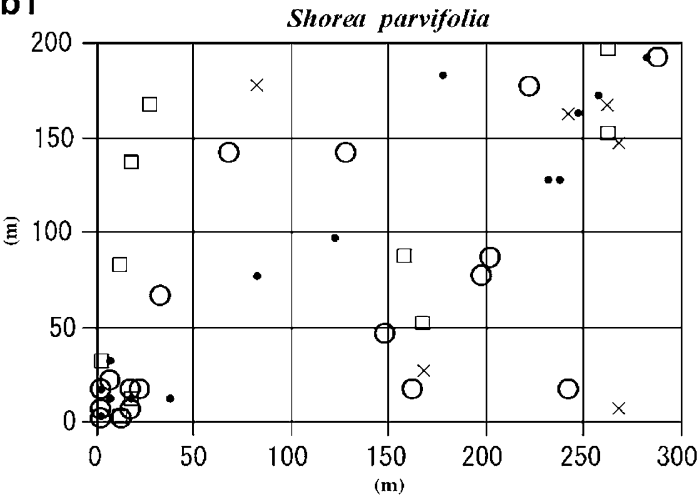

c1

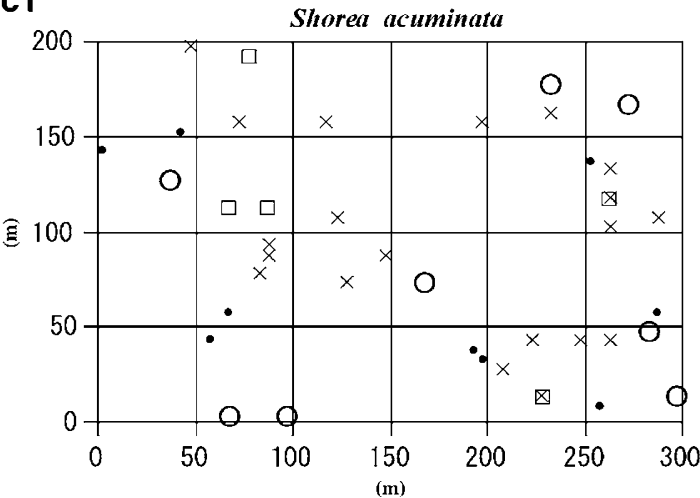

a2

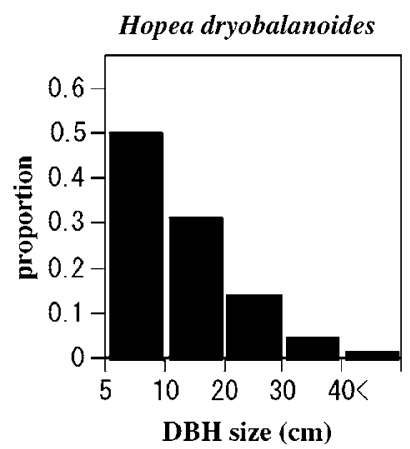

b2

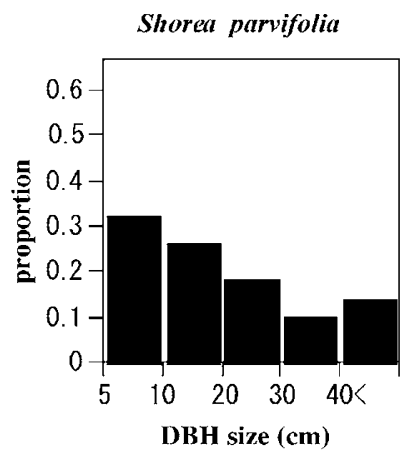

c2

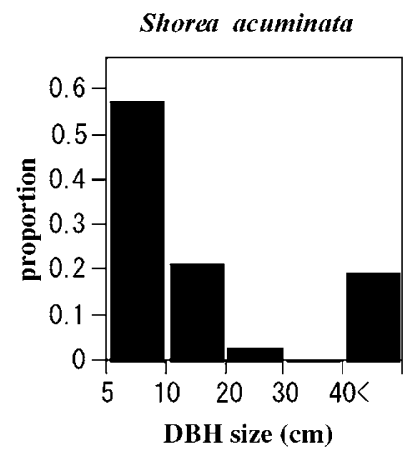

Figure 1 Spatial distribution of (a-1) H. dryobalanoides, (b-1) S. parvifolia and (c-1) S. acuminata in the 6-ha plot. The unfilled circles indicate trees with dbh $>30 \mathrm{~cm}$, squares are $20-30 \mathrm{~cm}$, filled circles are $10-20 \mathrm{~cm}$ and crosses are $5-10 \mathrm{~cm}$. dbh frequency classes are also shown for (a-2) H. dryobalanoides, (b-2) S. parvifolia and (c-2) S. acuminata. 
$30 \mathrm{~s}$ at the optimized annealing temperature and $30 \mathrm{~s}$ at $72{ }^{\circ} \mathrm{C}$, with a final $3 \mathrm{~min}$ incubation at $72^{\circ} \mathrm{C}$, using a GeneAmp $^{\mathrm{TM}}$ PCR System Model 9700 (PE Applied Biosystems). Genotypes were determined using an ABI 310 Genetic Analyzer and GeneScan ${ }^{\mathrm{TM}}$ software Ver. 2.0.1 (PE Applied Biosystems).

\section{Data analysis}

For each locus, the allele frequency and observed heterozygosity $\left(H_{\mathrm{o}}\right)$ were calculated. In addition, the expected heterozygosity $\left(H_{\mathrm{e}}\right)$, effective number of alleles $\left[N_{\mathrm{e}}=1 /\left(1-H_{\mathrm{e}}\right)\right]$ and fixation index $\left(F_{\mathrm{IS}}\right)$ were estimated according to Nei (1987), and deviations from HardyWeinberg equilibrium were tested by the method of $\mathrm{Li}$ and Horvitz (1953).

Genetic relatedness between all individuals of each species was calculated using Relatedness Software, version 5.0.8 (Goodnight, 2001) based on Queller and Goodnight (1989). The spatial distances were also calculated between pairs of all individuals of each species. The statistical test for correlation between the genetic relatedness and spatial distances among all individuals was performed using The $R$ Package for Multivariate and Spatial Analysis version 4.0 (Casgrain and Legendre, 2000) with 5000 randomizations, which is a realistic minimum for establishing a significance level of about 0.01 (Manly, 1997). Genetic clustering would be expected when this correlation is significant.

Morishita's index of dispersion $\left(I_{\delta}\right)$ was calculated to assess the spatial distribution of individuals of the three dipterocarp species (Morishita, 1959). If individuals are randomly distributed over the plot, $I_{\delta}=1$; if individuals are patchily distributed, $I_{\delta}>1$; and if individuals are uniformly distributed, $I_{\delta}<1$. The significance of the departure from randomness was tested using F-statistics.

\section{Estimation of seed dispersal distance}

Generally, the seed dispersal distance of wind-dispersed species is determined by three parameters: wind speed, tree height and terminal velocity of the seed (Green and Johnson, 1989)

$$
X=\sum \frac{u(H)}{F(H)}
$$

where $u(H)$ is wind speed at height $H$ meters and $F(H)$ is terminal velocity of the seed at height $H$ meters. The measured terminal velocities of falling $S$. parvifolia and $S$. acuminata seeds were used as the $F(H)$ values, while the measured terminal velocity of $H$. mengarawan seeds was used for $H$. dryobalanoides, two related species with similar seed form (Ashton, 1982).

Wind speed varies depending on the vertical distance from the ground, so when estimating seed dispersal distances the vertical variation in wind speed was expressed as a function of height, using wind speed data collected at Pasoh (not shown):

$$
\begin{aligned}
& f u(H)=u_{53}(0.45 H-1.385) \\
& (40<\mathrm{H} 53) \\
& \quad f u(H)=u_{40} \exp ^{(-0.04(40-H))} 0
\end{aligned}
$$

$(0<\mathrm{H} 40)$ where $f u(H)$ is wind speed at height $H$ meters, while $u_{40}$ and $u_{53}$ are the wind speeds at 40 and $53 \mathrm{~m}$, respectively.

\section{Results}

Spatial distribution patterns of individuals

Individuals of all three dipterocarp species examined in this study exhibited clumped distributions at all quadrat sizes, according to Morishita's index of dispersion (Table 1). For H. dryobalanoides and S. parvifolia, clumping was strong and significant, but although there were indications of a clumped distribution in S. acuminta, it was not statistically significant (Table 1).

\section{Genetic diversity}

In $H$. dryobalanoides, PCR products were successfully detected for all individuals at five loci: Shc02, Shc09, Nhe04, Nhe05 and Nhe18. The expected heterozygosity $\left(H_{\mathrm{e}}\right)$ ranged from 0.54 to 0.76 , with the number of alleles ranging from three to nine (Table 2a). For S. parvifolia, PCR products were obtained for all individuals at five microsatellite loci: Shc02, Shc03, Shc04, Shc09 and Nhe04. The expected heterozygosity $\left(H_{\mathrm{e}}\right)$ ranged from 0.33 to 0.85 , with the number of alleles ranging from four to 18 (Table 2b). For S. acuminata, PCR products were successfully detected for all individuals at four microsatellite loci: Shc03, Shc04, Shc09 and Nhe04. The expected heterozygosity $\left(H_{\mathrm{e}}\right)$ ranged from 0.42 to 0.79 , with the number of alleles ranging from three to 10 (Table 2c).

Significant deviations from Hardy-Weinberg equilibrium were found at three loci (Nhe04, Nhe05 and Shc09) in H. dryobalanoides, at two loci (Shc04 and Shc09) in S. parvifolia and at one locus (Shc03) in S. acuminata. The deviations may have resulted from bias due to misamplification of loci caused by null alleles, leading to an apparent excess of homozygosity (Marshall et al, 1998).

\section{Spatial genetic structure}

The relationship between spatial distance and genetic relatedness is shown in Figure 2. When strong genetic structure within populations is present, a negative correlation with high $r$-values would be expected between these parameters. Significant, negative correlation was detected in $H$. dryobalanoides $(r=-0.301$, $P<0.01$; Figure 2a) and S. parvifolia $(r=-0.149, P<0.05$; Figure 2b), but the correlation was not significant in $S$. acuminata $(r=-0.050, P>0.05$; Figure $2 c)$. The results indicate that the level of genetic structure differed among the three species at the study site.

\section{Seed dispersal of three dipterocarps}

The estimated seed-dispersal distances for the three dipterocarp species differed (Figure 3), and corresponded with the order of degree of genetic structuring detected in them. The seed-dispersal distance would strongly correlate with the degree of genetic structures of the three species.

\section{Discussion}

A significant genetic structure was found in $H$. dryobalanoides and S. parvifolia, but not in S. acuminata. Notably, the genetic structure of $H$.dryobalanoides was greater than that of the two Shorea species (Figure 2). Since the study site appears to have no clear microhabitat heterogeneity, the difference in the degree of genetic structure among 
a

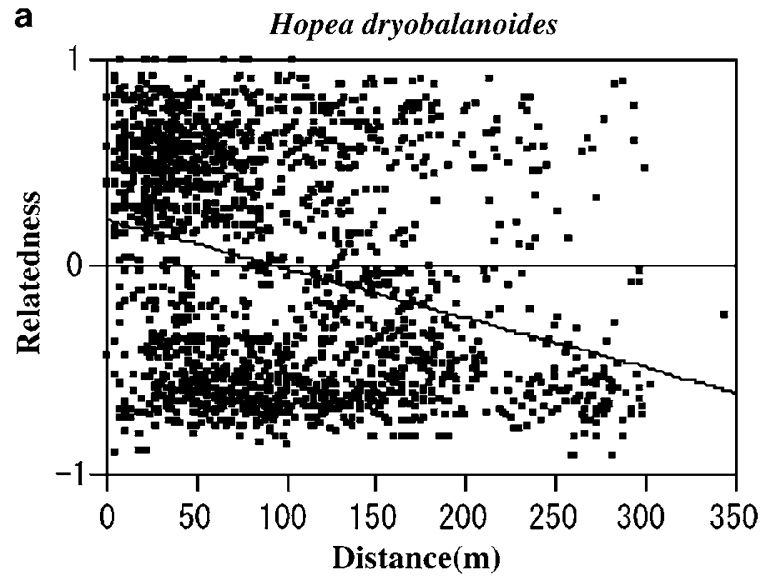

b

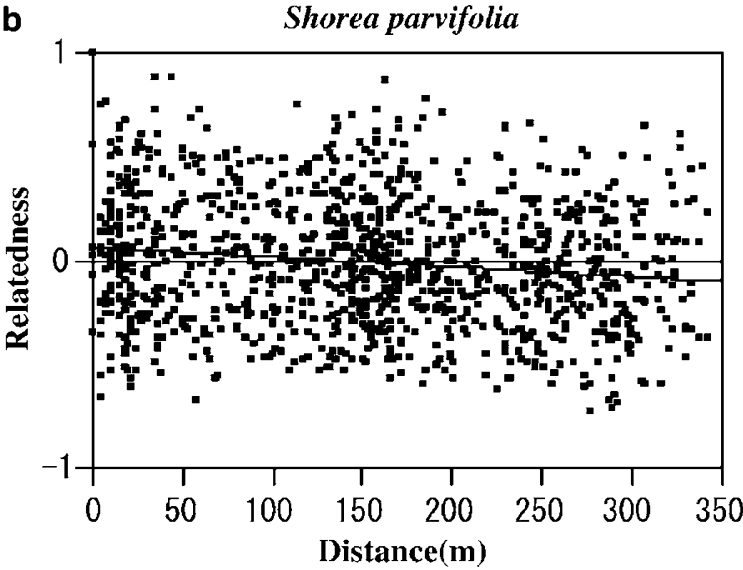

c

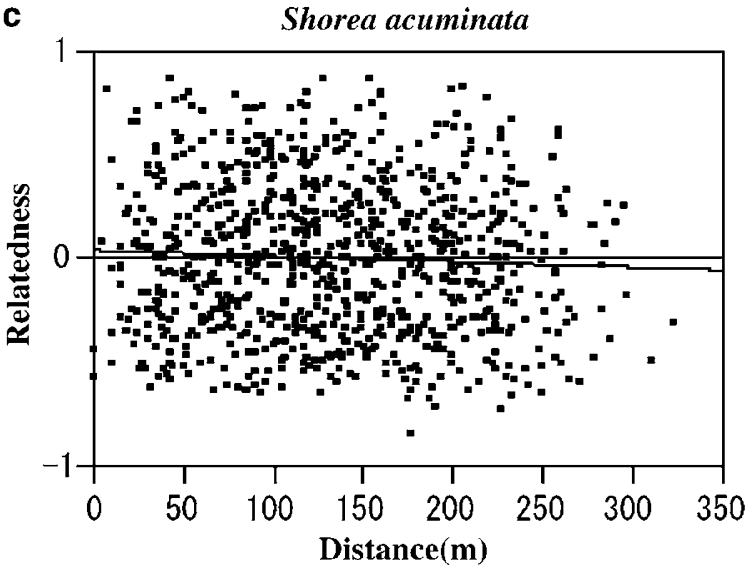

Figure 2 Relationship between spatial distance and relatedness for: (a) H. dryobalanoides, (b) S. parvifolia and (c) S. acuminata. The correlation is significant and negative in $H$. dryobalanoides and S. parvifolia $(H$. dryobalanoides, $r=-0.301, P<0.01$; S. parvifolia, $r=-0.149, P<0.05 ; 5000$ permutations, Mantel test (Mantel, 1967)), but it is not statistically significant in S. acuminata $(r=-0.0504$, $P>0.05,5000$ permutations, Mantel test).

these species is probably due to differences in gene dispersal, rather than selection.

The seeds of all three species are dispersed by wind or gravity, so the most obvious differences with respect to seed dispersal among these species are related to tree height. S. parvifolia and S. acuminata are canopy species, whereas $H$. dryobalanoides is a subcanopy species and the adult Shorea trees are $20 \mathrm{~m}$ or more taller on average than
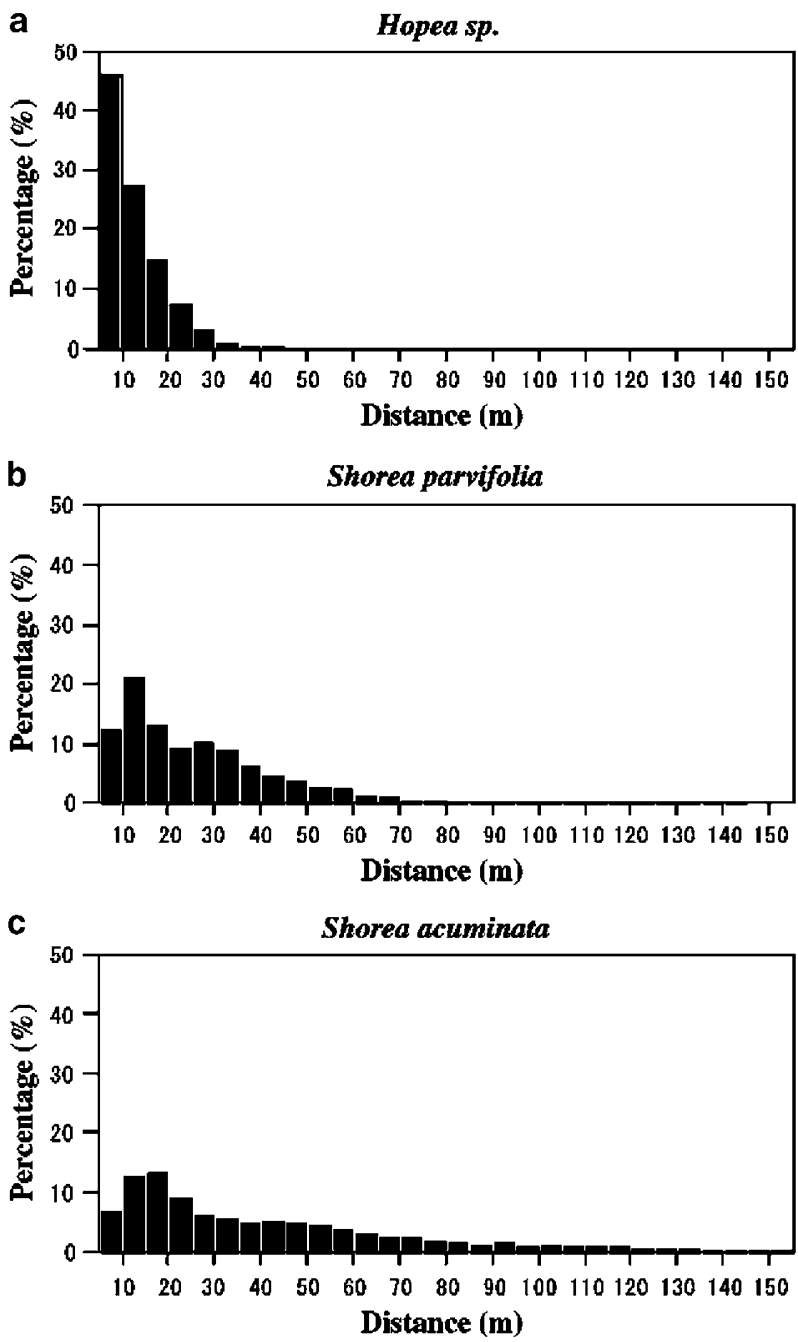

Figure 3 Estimated seed dispersal distance of: (a) Hopea sp (b) S. parvifolia and (c) S. acuminata. The horizontal axis shows the estimated seed dispersal distances, while the vertical axis is the frequency of each class as a proportion of the total. The maximum seed dispersal distance was about $500 \mathrm{~m}$ in S. acuminata (not shown).

the Hopea trees. This suggests that the seed shadows differ among these species since it depends on the height of the release point; taller trees can disperse their seed more extensively. The seed dispersal distance for three dipterocarps clearly indicates the difference of the seed shadows, which may be a major contributory factor to differences of the spatial genetic structure among the species.

Generally, the main causes of clumped distribution patterns within a forest are related to seed dispersal patterns and/or habitat heterogeneity (Manabe and Yamamoto, 1997). The results of the spatial distribution pattern analysis of these three dipterocarp species were consistent with the estimates of their seed dispersal distances (Table 1). Clumping may affect pollinator behavior, resulting in nearest-neighbor pollination or inbreeding (Levin, 1984), and it tends to promote the genetic structure. A simulation study has also shown that the presence of strong clumping leads to a slight increase in spatial autocorrelation, caused by limited dispersal of seed and pollen (Doligez et al, 1998). 
The genetic structure of adult trees $(\mathrm{dbh}>30 \mathrm{~cm})$ of $N$. heimii in a 42-ha plot (Konuma et al, 2000) was also significant, with a negative correlation between relatedness and spatial distance $(r=-0.228)$. Thus, it seems that the degree of genetic structure in $N$. heimii is stronger than that of the two Shorea spp but weaker than that of $H$. dryobalanoides, because $N$. heimii is also an emergent tree, and seed dispersal distance is limited to a radius of around $20 \mathrm{~m}$ (Konuma et al, 2000). Boshier et al (1995) reported that Cordia alliodora, a neotropical tree with a range of seed dispersal limited to ca. $20 \mathrm{~m}$, showed a positive relationship between genetic relatedness and spatial proximity. Another study by Hamrick et al (1993) showed that the genetic structure of wind-dispersed species was stronger than that of animal-dispersed species. Thus, all of these studies showed that the seed dispersal distance affects the spatial genetic structure, which is consistent with our results.

Pollen flow is another important factor that affects the genetic structure (Loveless and Hamrick, 1984), since extensive pollen flow results in weak genetic structure. This has already been confirmed for several tropical species (Doligez and Joly, 1997; Konuma et al, 2000). Unfortunately, the pollen flow distances of the three species analyzed in the present study are not known. The only relevant reports so far suggest that the main pollinators are thrips and/or small beetles in Shorea spp, and likely flies in H. dryobalanoides (Appanah, 1987). To assess the effect of pollen flow on the genetic structure of these three species, we need to estimate the pollen flow distances when flowering occurs. Finally, we would understand how the contribute to pollen flow and seed dispersal for the spatial genetic structure of each species in this plot.

We also found that the genetic structure of S. parvifolia was stronger than that of $S$. acuminata, which may be due to differences in self-compatibility between the two species, since self-incompatibility has been reported in S. acuminata (Chan, 1981). The breeding system is an important factor affecting the genetic structure in plant populations (Nason et al, 1997), and outcrossing would tend to decrease the genetic structure (Loveless and Hamrick, 1984). To assess the effect of self-incompatibility on the genetic structures in these three species, it will be necessary to investigate their breeding systems, especially their respective degrees of self-incompatibility.

Tropical forests in Peninsular Malaysia have become increasingly affected by human activity, especially selective logging and issues related to the conservation and sustainable use of the tropical forests are increasing in importance (Ratnam et al, 1999). However, there is a scarcity of relevant data for developing sustainable forest management guidelines and effective conservation strategies such as selective logging. Obayashi et al (2002) reported that there has been a considerable increase in the selfing rate in a logged forest of $S$. curtisii, although there was no difference in the genetic diversity of adult trees between the primary and the logged forest. In other Shorea sp, there have been suggestions that inbreeding is increased in logged forest (Murawski et al, 1994). In this study, we found that each species has a different level of within-population genetic structure. If a population with strong genetic structure is conducted selective logging without consideration of its structure, probability of mating with relatives may increase. Studies on genetic structure provide not only fundamental data on forest genetics but also essential information for understanding tropical trees and developing more effective and sensitive ways to exploit them.

Table 2 Profiles of microsatellite loci detected in (a) $H$. dryobalanoides, 64 trees, (b) S. parvifolia, 50 trees, and (c) S. acuminata, 46 trees

\begin{tabular}{lrrrr}
\hline Locus & $\mathrm{N}_{a}$ & $\mathrm{H}_{o}$ & $\mathrm{H}_{e}$ & $\mathrm{~F}_{I S}$ \\
\hline $\begin{array}{l}\text { (a) H. dryobalanoides } \\
\text { Nhe04 }\end{array}$ & 4 & 0.60 & 0.67 & \\
Nhe05 & 3 & 0.67 & 0.54 & $-0.10^{* *}$ \\
Nhe18 & 9 & 0.69 & 0.76 & 0.09 \\
Shc02 & 7 & 0.70 & 0.75 & 0.07 \\
Shc09 & 5 & 0.56 & 0.67 & $0.15^{* *}$ \\
& & & & \\
(b) S. parvifolia & & & & 0.19 \\
Nhe04 & 4 & 0.38 & 0.46 & -0.03 \\
Shc02 & 6 & 0.34 & 0.33 & 0.19 \\
Shc03 & 5 & 0.38 & 0.47 & $0.43^{* *}$ \\
Shc04 & 14 & 0.48 & 0.85 & $0.28^{* *}$ \\
Shc09 & 18 & 0.60 & 0.84 & \\
(c) S. acuminata & & & & 0.21 \\
Nhe04 & 4 & & & $0.39^{* *}$ \\
Shc03 & 3 & 0.33 & 0.42 & 0.17 \\
Shc04 & 10 & 0.33 & 0.55 & 0.00 \\
Shc09 & 10 & 0.66 & 0.79 & 0.76 \\
\hline
\end{tabular}

The number of alleles detected $\left(N_{\mathrm{a}}\right)$, observed heterozygosity $\left(H_{\mathrm{o}}\right)$ expected heterozygosity $\left(H_{\mathrm{e}}\right)$, and fixation index $\left(F_{\mathrm{IS}}\right)$ are shown The deviations from Hardy-Weinberg equilibrium were assessed using a $\chi^{2}$ goodness-of-fit test.

$* * P<0.01$

Table 1 Values of Morishita's index of distribution $\left(I_{\delta}\right)$ for H. dryobalanoides, S. parvifolia, and S. acuminata (dbh $\leqslant 5 \mathrm{~cm}$ )

\begin{tabular}{|c|c|c|c|c|c|c|c|}
\hline \multirow[t]{2}{*}{ Quadrat size $\left(m^{2}\right)$} & \multirow[t]{2}{*}{ Number of quadrat in 6 ha } & \multicolumn{2}{|c|}{ Hopea dryobalanoides } & \multicolumn{2}{|c|}{ Shorea parvifolia } & \multicolumn{2}{|c|}{ Shorea acuminata } \\
\hline & & $\mathrm{I}_{\delta}$ & $\mathrm{F}$ & $\mathrm{I}_{\delta}$ & $\mathrm{F}$ & $\mathrm{I}_{\delta}$ & $\mathrm{F}$ \\
\hline $150 \times 100$ & 4 & 1.88 & $19.38^{* * *}$ & 1.33 & $6.62^{* * *}$ & 0.97 & 0.48 \\
\hline $100 \times 100$ & 6 & 2.53 & $20.31^{* * *}$ & 1.69 & $8.02^{* * *}$ & 1.01 & 1.09 \\
\hline $50 \times 50$ & 24 & 2.64 & $5.5^{* * *}$ & 4.24 & $8.17^{* * *}$ & 1.22 & 1.44 \\
\hline $25 \times 25$ & 96 & 4.86 & $3.56^{* * *}$ & 9.41 & $5.52^{* * *}$ & 1.15 & 1.07 \\
\hline
\end{tabular}

If individuals are randomly distributed over the plot, $I_{\delta}=1$; if individuals are patchily distributed, $I_{\delta}>1$; and if individuals are uniformly distributed, $I_{\delta}<1$.

The significance was tested by calculating F-statistics.

*** $P<0.001$. 


\section{Acknowledgements}

We thank the staff of FRIM and Drs K Seiwa, Y Suyama, H Iwata, T Nagamitsu and Ms Naito of the Pasoh Forest Reserve for assistance during field investigations, and members of the Genetics Unit in FRIM and the Genome Analysis Lab in the FFPRI for help in laboratory work and encouragement. We also thank Professor M Tani of Kyoto University for providing the wind speed data of Pasoh meteorology station. This study was supported by Grant No. E-4 under the Global Environment Research Program of the Ministry of Environment in Japan.

\section{References}

Alvarez-Buylla ER, Chaos A, Pinero D, Garay AA (1996). Demographic genetics of a pioneer tropical tree species: patch dynamics, seed dispersal, and seed banks. Evolution 50: 1155-1166.

Appanah S (1981). Pollination in Malaysian primary forest. Malays For 44: 37-42.

Appanah S (1987). Insect pollinators and the diversity of Dipterocarps.. Proceedings of the Third Round Table Conference on Dipterocarpus. UNESCO: Jakarta, Indonesia. 277-291.

Ashton PS (1982). Dipterocarpaceae. In: Flora Malesiana, Series ISpermatophyta. Flowering Plants. Martinun Nijhoff Publishers: The Hague, The Netherlands. Part 2, Vol. 9pp 552.

Berg EE, Hamrick JL (1995). Fine-scale genetic structure of a Turkey oak forest. Evolution 49: 110-120.

Boshier DH, Chase MR, Bawa KS (1995). Population genetics of Cordia alliodora (Boraginaceae), a neotropical tree. 3. Gene flow, nseighborhood, and population substructure1. Am J Bot 82: 484-490.

Casgrain P, Legendre P (2000). The R Package for Multivariate and Spatial Analysis, Version 4.0. University of Montreal: Montreal, Quebec.

Chan HT (1981). Reproductive biology of some Malaysian dipterocarps. III. Breeding systems. Malays For 44: 28-36.

Doligez A, Baril C, Joly HI (1998). Fine-scale genetic structure with nonuniform distribution of individuals. Genetics 148: 905-919.

Doligez A, Joly H (1997). Genetic diversity and spatial structure within a natural stand of a tropical forest tree species, Carapa procera (Meliaceae) in French Guiana. Heredity 79: 72-82.

Geburek T, Trippknoeles P (1994). Genetic architecture in bur oak, Quercus macrocarpa (Fagaceae), inferred by means of spatial autocorrelation analysis. Plant Syst Evol 189: 63-74.

Goodnight KF (2001). Relatedness. version 5 .0.5, http:// www.gsoftnet.us/GSoft.html.

Green DF, Johnson EA (1989). A model of wind dispersal of winged or plumed seeds. Ecology 70: 339-347.

Hamrick JL, Murawski DA, Nason JD (1993). The influence of seed dispersal mechanisms on the genetic structure of tropical tree populations. Vegetatio 107/108: 281-297.

Hamrick JL, Nason JD (1996). Consequence of dispersal in plants. In: Rhodes OE, Ronald KC, Smith MH (eds) Population Dynamics in Ecological Space and Time. The University of Chicago Press: Chicago. pp 203-235.

Iwata H, Konuma A, Tsumura Y (2000). Development of microsatellite markers in the tropical tree Neobalanocarpus heimii (Dipterocarpaceae). Mol Ecol 9: 1684-1685.

Konuma A, Tsumura Y, Lee C, Lee S, Okuda T (2000). Estimation of gene flow in the tropical-rainforest tree Neobalanocarpus heimii (Dipterocarpaceae), inferred from paternity analysis. Mol Ecol 9: 1843-1852.
Levin DA (1984). Inbreeding depression and proximity-dependent crossing success in Phlox drummondii. Evolution 38: 116-127.

Li CC, Horvitz DG (1953). Some methods of estimating the inbreeding coefficient. Am J Hum Genet 5: 107-117.

Loiselle BA, Sork VL, Nason J, Graham C (1995). Spatial genetic structure of a tropical understory shrub Psychotria officinalis (Rubiaceae). Am J Bot 82: 1420-1425.

Loveless MD, Hamrick JL (1984). Ecological determinants of genetic structure in plant populations. Annu Rev Ecol Syst 15: 65-95.

Manabe T, Yamamoto S (1997). Spatial distribution of Eurya japonica in an old-growth evergreen broad-leaved forest, SW Japan. J Veg Sci 8: 761-772.

Manokaran N, LaFrankie JV, Kochummen KM, Quah ES, Klahn JE, Ashton PS et al. (1992). Stand Table and Distribution of Species in the 50-ha Research Plot at Pasoh Forest Reserve. FRIM Research Data No. 1. Forest Research Institute Malaysia: Kuala Lumpur.

Manly BFJ (1997). Randomization, Bootstrap and Monte Carlo Methods in Biology, 2nd edn. Chapman \& Hall: UK.

Mantel N (1967). The detection of disease clustering and a generalized regression approach. Cancer Res 27: 209-220.

Marshall TC, Slate J, Kruuk LEB, Pemberton JM (1998). Statistical confidence for likelihood-based paternity inference in natural populations. Mol Ecol 7: 639-655.

Morishita M (1959). Measuring of the dispersion of individuals and analysis of the distributional patterns. Memoirs of the Faculty of Science, Kyusyu University. Ser E Biol 2: 215-235.

Murawski DA, Gunatilleke IAUN, Bawa KS (1994). The effects of selective logging on inbreeding in Shorea megistophylla (Dipterocarpaceae) from Sri Lanka. Conserv Biol 8: 997-1002.

Nason JD, Aldrich PR, Hamrick JL (1997). Dispersal and the dynamics of genetic structure in fragmented tropical tree populations. In: Laurance WF, Bierregard RO ( eds ) Tropical Forest Remnants: Ecology, Management and Conservation of Fragmented Communities. University of Chicago Press: Chicago, USA. pp 304-320.

Nei M (1987). Molecular Evolutionary Genetics. Columbia University Press: New York.

Obayashi K, Tsumura Y, Ihara-Ujino T, Niyama K, Tanouchi H, Suyama Y et al. (2002). Genetic diversity and outcrossing rate between undisturbed and selectively logged forest of Shorea curtisii (Dipterocarpaceae) using microsatellite DNA analysis. Int J Plant Sci 163: 151-158.

Queller DC, Goodnight KF (1989). Estimating relatedness using genetic markers. Evolution 43: 258-275.

Ratnam W, Lee CT, Muhammad N, Boyle TJB (1999). Impact of logging on genetic diversity in humid tropical forest. In: Matyas S (ed ) Forest Genetics and Sustainability, Vol. 63. Kluwer Academic Publications: Dordrecht, The Netherlands. pp 171-181.

Tsumura Y, Kawahara T, Wickneswari R (1996). Molecular phylogeny of Dipterocarpaceae in Southeast Asia using RFLP of PCR-amplified chloroplast genes. Theor Appl Genet 93: 22-29.

Ueno S, Tomaru N, Yoshimaru H, Manabe T, Yamamoto S (2000). Genetic structure of Camellia japonica L. in an oldgrowth evergreen forest, Tsushima, Japan. Mol Ecol 9: 647-656.

Ujino T, Kawahara T, Tsumura Y, Nagamitsu T, Toshimaru H, Ratnam W (1998). Development and polymorphism of simple sequence repeat DNA markers for Shorea curtisii and other Dipterocarpaceae species. Heredity 81: 422-428.

Wright S (1943). Isolation by distance. Genetics 28: 114-138. 